\title{
Contribution of limbs' actions to the four competitive swimming strokes: a nonlinear approach
}

\author{
Raul F. Bartolomeu, Mário J. Costa \& Tiago M. Barbosa
}

To cite this article: Raul F. Bartolomeu, Mário J. Costa \& Tiago M. Barbosa (2018): Contribution of limbs' actions to the four competitive swimming strokes: a nonlinear approach, Journal of Sports Sciences, DOI: 10.1080/02640414.2018.1423608

To link to this article: https://doi.org/10.1080/02640414.2018.1423608

Submit your article to this journal $₫$

Q View related articles ¿

View Crossmark data $\complement$ 


\title{
Contribution of limbs' actions to the four competitive swimming strokes: a nonlinear approach
}

\author{
Raul F. Bartolomeu (1) $\mathrm{a}, \mathrm{b}$, Mário J. Costa $\mathbb{1}^{\mathrm{b}, \mathrm{c}}$ and Tiago M. Barbosa (10) \\ ${ }^{a}$ Department of Sport Sciences, Exercise and Health, University of Trás-os-Montes and Alto Douro, Vila Real, Portugal; ${ }^{b}$ Research Center in Sports \\ Sciences, Health and Human Development (CIDESD), Vila Real, Portugal; 'Department of Sport Sciences, Polytechnic Institute of Guarda, Guarda,

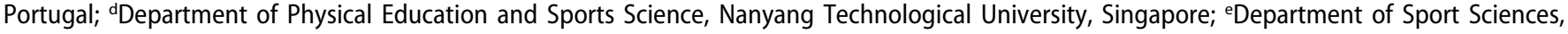 \\ Polytechnic Institute of Bragança, Bragança, Portugal
}

\section{ABSTRACT}

The aim of our study was to assess the effect of the limbs' actions on the nonlinear properties of the four competitive swimming strokes. Forty-nine swimmers performed all-out sprints at front-crawl, backstroke, breaststroke and butterfly, each one at full stroke (FS), only the arms' stroke (AS), and only leg kicking (LK), in a total of 12 bouts, 6 per day. A speedo-meter cable was attached to the swimmer's hip, to collect the speed-time raw data $(f=50 \mathrm{~Hz})$. Velocity, speed fluctuation, sample entropy and fractal dimension were derived from the speed-time series. Significant and moderatestrong effects were noted for both stroke and condition in all variables in the study ( $p \leq 0.001$; $0,560<\eta^{2}<0,952$ ). The four competitive strokes and their three conditions exhibited nonlinear properties. The swimming pattern was less complex and more predictable for LK in comparison to AS and FS. Breaststroke and butterfly have more complex but more predictable patterns than backstroke and front-crawl.

\section{ARTICLE HISTORY}

Accepted 6 December 2017

\section{KEYWORDS}

Swimming; dynamical

systems; nonlinear variables; sample entropy; fractal dimension

\section{Introduction}

Swimming is an aquatic locomotion technique defined by periodic actions of the upper and lower limbs to overcome the drag force and propel the body forward (Barbosa, Costa, Morais, et al., 2013).

In front-crawl, the contribution of the arm's stroke to the overall swimming speed (i.e. full stroke performing the strokepull and the kicking) is approximately $87-90 \%$ (Hollander, de Groot, van Ingen Schenau, Kahman, \& Toussaint, 1988; Ribeiro et al., 2015; Watkins \& Gordon, 1983). On the other hand, leg kicking seems to have a partial contribution to the overall swimming speed of approximately $10-13 \%$. As far as our understanding goes, the previous studies assessed the difference between the speeds performing the full stroke (i.e. concurrent flutter kicking and stroke-pull) and the arm stroke (i.e. only stroke-pull) to estimate the contribution of the kicking. One may argue that this approach can impose an underestimation of the contribution by the kicking to overall speed. However, this remains to be cleared. Moreover, all studies focused on front-crawl stroke, disregarding the partial contribution of lower and upper limbs actions to the overall speed in the remaining swimming strokes.

During swimming, horizontal velocity of the body displacement changes over each stroke cycle. These changes occur both in value and in direction, due to the non-uniform periodic actions of the lower and upper limbs. This intra-cyclic variation of the horizontal velocity of the body is also known as "speed fluctuation". This fluctuation within each stroke cycle can be tested by classical biomechanics (Barbosa et al., 2005; Miyashita, 1971). This parameter is higher in breaststroke and butterfly compared to frontcrawl and backstroke (Barbosa et al., 2006, 2013). Both swim velocity and speed fluctuation have been reported as a good proxy of performance and efficiency, respectively (Barbosa, Costa, \& Marinho, 2013).

An alternative assessment of human locomotion are nonlinear parameters.

The nonlinear parameters selected on regular basis aim to provide insight on the entropy and fractal proprieties of human locomotion techniques. Both entropy and fractal analysis have been used to study a wide range of systems in medicine and biomechanics, for example the variability of the heart rate in an electrocardiogram (Madeiro, Seisdedos, Cortez, \& Marques, 2013) and the human gait (Hausdorff, Peng, Ladin, Wei, \& Goldberger, 1995; Schiffman, Chelidze, Adams, Segala, \& Hasselquist, 2009; Wuehr et al., 2013) where evidences were found that human walking showed long-time correlations in the time series, thus presenting a fractal-like behavior.

Two variables are reported very often to assess the entropy: (i) the approximate entropy and; (ii) the sample entropy. Although Approximate Entropy is reported in a large variety of scientific fields, which enables comparisons, its algorithm is largely dependent on the length of the data-series and may lack relative consistency (Chen, Zhuang, Yu, \& Wang, 2009; Richman \& Moorman, 2000; Yentes et al., 2013), unlike Sample Entropy (SampEn). 
SampEn is the negative natural logarithm of the conditional probability that two sequences similar for $m$ points remain similar at the next point. Therefore, the lower the SampEn value, the greater the self-similarity in the time-series, thus, the greater the regularity and the predictability of this parameter. In human swimming, there are up to four limbs moving concurrently. In training sessions, swimmers may often undergo sets performing only kicking or the stroke-pull. Having different limbs and number of limbs in action, may impose changes in the motor behavior and hence in the entropy (i.e., changing its predictability).

The fractal analysis focuses on the time-evolutionary properties of data-series and on their correlation structure (Delignieres et al., 2006). The value at a particular time is related not only to the immediately preceding values but also to fluctuations in the remote past (Delignieres et al., 2006). One of the most common ways to calculate the Fractal Dimension (FD) relies on the Higuchi's algorithm. The FD provides information about the intra-cyclic complexity and irregularity of a given time-series' variations. The lower the value, the less complex and irregular the motor behavior is. There are other ways of calculation the FD, for instance, the Petrosian's and the Katz's algorithm. However, Higuchi's algorithm is reported to be more accurate in calculating the FD of a time-series (Esteller, Vachtsevanos, Echauz, \& Litt, 2001; Wang, Sourina, \& Nguyen, 2011).

Our understanding is that there is no report in the literature regarding the effect of different limbs' actions on the nonlinear parameters. One might hypothesize that the use of only the upper or lower limbs might influence the motor behavior, thus making it less complex than the full stroke (i.e. concurrent action by lower and upper limbs).

One of the perspectives in the motor control learning process is based on the constraint-led approach. The constraints can be environmental, organismic or related to the task (Newell, 1986). In opposition to the traditional theories of skill acquisition, this approach views the motor control learning process as an ongoing dynamic process involving a search for and a stabilization of specific, functional movement patterns as each individual adapts to a variety of changing constraints (Davids, Button, \& Bennett, 2008). This theoretical framework is complemented by the nonlinear pedagogy, which involves manipulating key task constraints on learners to facilitate the emergence of functional movement patterns and decision-making behaviors (Chow et al., 2006). Thus, through the manipulation of specific constraints, in this case complexity and predictability, teachers/ coaches are able to assist the learner's search for more effective coordination patterns and behaviors, that are needed to overcome the proposed task (Araújo, Davids, Bennett, Button, \& Chapman, 2004; Chow et al., 2006). However, to properly manipulate these specific constraints, one has to deeply understand how they affect the behavior and the task of the swimmer.

The aim of our study was to assess the effect of the limbs' actions on the nonlinear properties of the swimming pattern of the four competitive swimming strokes. It was hypothesized that: i) the segmental actions of the upper and lower limbs separately would make the pattern more predictable and less complex than the full stroke; ii) both arms and legs alone as well as the full body stroke would influence the nonlinear properties of the swimming strokes, and influence them differently.

\section{Methods}

\section{Participants}

Forty-nine swimmers were recruited to take part in this research ( 24 boys and 25 girls, $14.20 \pm 1.71$ years old). The participants were swimmers with training volumes of approximately 16,000 meters per week, from regional to national level, which personal records at $100 \mathrm{~m}$ freestyle represent $73,29 \%$ of the world record for boys and $70,97 \%$ for girls. As inclusion criteria, the following parameters were considered: (i) being a competitive swimmer; (ii) at least 2 years of experience; (iii) competing at regional and/or national events; (iv) not having a muscle-skeletal or neurologic injury in the past 6 months.

All procedures were in accordance with the Helsinki Declaration regarding human research, and with the research design being approved by the University's Institutional Review Board. All coaches, parents/guardians and swimmers gave their informed written consent for the participation in this study.

\section{Protocol}

The trials took place in two different pools: in one of them at the morning period with the water temperature at a mean of $28,5^{\circ} \mathrm{C}$, and the other at the afternoon period with the water temperature at a mean of $29^{\circ} \mathrm{C}$. The swimmers performed a $1000 \mathrm{~m}$ standard warm-up beforehand. Each swimmer performed $25 \mathrm{~m}$ all-out sprints at front-crawl, backstroke, breaststroke and butterfly (counterbalanced randomly assigned crossover design). Three conditions were selected for each swimming stroke: (i) the full stroke (i.e., arms' stroke-pull plus kicking, full stroke; FS); (ii) arms' stroke-pull (i.e. only the arms' stroke; AS) and only the kicking (i.e., leg kicking; LK). Ten athletes were randomly assigned at each time and their evaluations took place in two consecutive days, as only two swimming strokes (at all three conditions) were swam per day. Overall, each swimmer undertook 3 bouts per competitive swimming stroke, in a total of 12 bouts, 6 for each day. All bouts started in-water and swimmers were encouraged to begin to swim right after the push-off, gliding and dolphinkicking as less as possible in this phase. Every swimmer rested for at least a 30min between bouts to ensure a total recovery. The nearby lanes were empty to reduce drafting, drag and other potential confounding factors on the data.

\section{Data collection}

A mechanical system to measure swimming velocity (Swim speedo-meter, Swimsportec, Hildesheim, Germany) was placed on a starting block in head-wall of the swimming pool. A cord was attached from the speedo-meter to the swimmer's hip. The signal was acquired at a frequency of $50 \mathrm{~Hz}$ and 
transmitted by a 12-bit acquisition card (USB-6008, National Instruments, Austin, Texas, USA) to a software interface in LabView (v.2010. National Instruments, Austin, USA), which displays the speed-time data in real time. Data were then exported to a signal-processor software (AcqKnowledge v.3.5, Biopac Systems, Santa Barbara, USA and filtered with a $5 \mathrm{~Hz}$ cut-off low-pass 4th order Butterworth filter upon residual analysis. The push-off from the wall (first five meters) and the finish (last meter) were discarded from the analysis to avoid the high variance in the motor behavior that are not caused by the swim stroke.

\section{Kinematic variables}

Mean velocity was calculated on the signal-processor software. The intra-cyclic variation of the horizontal velocity of the hip was calculated as reported in the literature (Barbosa et al., 2013) as:

$$
d v=\frac{\sqrt{\frac{\sum_{i}\left(v_{i}-v\right)^{-2} \cdot F_{i}}{n}}}{\frac{\sum_{i} v_{i} \cdot F_{i}}{n}} \cdot 100
$$

where $d v$ is the speed fluctuation, $v$ is the swimming mean velocity, $v_{i}$ is the swimming instantaneous velocity, $F_{i}$ is the acquisition frequency and $n$ is the number of observations.

The mean velocity and $d v$ were measured between the 11 th and the 24th meters from the head-wall to remove the effect of both start and finish.

\section{Nonlinear parameters}

SampEn was computed by the algorithm proposed by Richman and Moorman (2000) on a MatLab routine (v.R20013a, MathWorks, Natick, USA) and calculated as:

$$
\operatorname{SampEn}(m, r, N)=-\ln \frac{A}{B}
$$

Where SampEn is the sample entropy, $m$ is the length of sequences to be compared, $r$ is the tolerance for accepting matches, $N$ is the length of the time series and $A / B$ is the conditional probability that two sequences within a tolerance $r$ for $m$ points remain within $r$ of each other at the next point (Robeva et al., 2007). $A$ is the total number of forward matches of length $m+1$ and $B$ is the total number of template matches of length $m$, calculated as:

$$
\begin{aligned}
& A=\left[\frac{(N-m-1)(N-m)}{2}\right] A^{m}(r) \\
& B=\left[\frac{(N-m-1)(N-m)}{2}\right] B^{m}(r)
\end{aligned}
$$

Where $A_{m}(r)$ is the probability that two sequences will match for $m+1$ points and $B_{m}(r)$ is the probability that two sequences will match for $m$ points, calculated as:

$$
A^{m}(r)=(N-m)^{-1} \sum_{i=1}^{N-m} A_{i}^{m}(r)
$$

$$
B^{m}(r)=(N-m)^{-1} \sum_{i=1}^{N-m} B_{i}^{m}(r)
$$

Where $A_{i}^{m}(r)$ is $(N-m-1)^{-1}$ times the number of vectors $x_{m+1}(j)$ within $r$ of $x_{m+1}(i)$, where (j) ranges from 1 to $N-m$ and $j \neq i$ and $B_{i}^{m}(r)$ is $(N-m-1)^{-1}$ times the number of vectors $x_{m}(j)$ within $r$ of $x_{m}(i)$, where $j$ ranges from 1 to $N-m$, and $j \neq i$ to exclude selfmatches.

Yentes et al. (2013) and Richman and Moorman (2000) suggested that time-series records should be larger than 200 points and 100 points, respectively, to reduce the bias of correlation templates to $<3 \%$. Hence, our $N$ was set to be higher than 500 speed-time pairs. There is no standardized combination of the length of sequences to be compared $(\mathrm{m})$ and the tolerance value $(r)$, only generally accepted values ranging from $1<m<3$ and $0.1<r<0.25$ (Davids, Hristovski, Serre, Button, \& Passos, 2014; Richman \& Moorman, 2000; Robeva et al., 2007; Yentes et al., 2013). According to literature (Chen et al., 2009; Richman \& Moorman, 2000), values of $m=2$ and $r=0.2$ seem to be appropriate as it fits the theoretical values of SampEn for random numbers with a uniform distribution in data lengths between 500 and 1000 points; which is in tandem to what was used in our study.

The FD was computed by the Higuchi's algorithm (Higuchi, 1988) as this algorithm is the most accurate for the analysis of time-series (Esteller et al., 2001). This algorithm considers a given time series $x(1), x(2), x(3), \ldots, x(N)$ of a time interval equals to $k$ and constructs $k$ new time series as:

$$
\begin{aligned}
x_{m}^{k}= & x(m), x(m+k), x(m+2 k), \ldots, \\
& x\left(m+\frac{N-m}{k} k\right)(m=1,2, \ldots, k)
\end{aligned}
$$

Where $m$ is the initial time, $k$ is the interval time, $L\rfloor$ represents both $m$ and $k$ are integers. For each $x_{m}^{k}$, the lengths $L_{m}(k)$ are then calculated as:

$$
L_{m}(k)=\left\{\left(\sum_{i=1}^{\frac{N-m}{k}} \mid X(m+i k)-X(m+(i-1) k \mid) \frac{N-1}{\frac{N-m}{k} k}\right\} / k\right.
$$

Where $N$ is the total number of samples and the term $N-1 /$ $[(N-m) / k] k$ is a normalization factor for the curve length of $x_{m}^{k}$. The length of the curve $L(k)$ was then calculated for the time interval $k$ as the mean value over $k$ sets of $L_{m}(k)$, as:

$$
L(k)=\frac{1}{k} \sum_{m=1}^{k} L_{m}(k)
$$

Finally, $\log (L(k))$ was plotted against $\log (1 / k)$ and a straight line was fitted according to the least-square best-fitting procedure. The slope of the least-squares linear best fit is the estimate of the FD.

$$
D=\frac{d \log N(L(k))}{d \log (k)}
$$

Where $D$ is the fractal dimension, $N$ is the number of points from the speed-time series, $k$ is the scaling factor 
and $L$ is the length of the time series. The algorithm was also computed on a MatLab routine (v.R20013a, MathWorks, Natick, USA).

\section{Statistical analysis}

The Shapiro-Wilk test was used to test the normality of the data distribution. Descriptive statistics include the mean, 1 SD and 95\% of confidence interval. A two-way repeated measures ANOVA was performed to analyze the effect of swim stroke (front-crawl, backstroke, breaststroke and butterfly stroke) and stroke condition (FS, AS, LK) $(p<0.05)$ in each selected variable. Whenever needed, a repeated measures ANOVA with Bonferroni post hoc test was performed ( $p<0.05$ ). The assumptions of an ANOVA were tested. Every time the assumption of sphericity was violated, the Greenhouse-Geisser correction was used to adjust the degrees of freedom of the F-ratio. Eta Squared $\left(\eta^{2}\right)$ was calculated as the effect size index and considered as: (i) minimum effect size if $0.04<\eta^{2} \leq 0.25$; (ii) moderate effect size if $0.25<\eta^{2} \leq 0.64$; and (iii) strong effect size if $\eta^{2}>0.64$ (Ferguson, 2009). All statistical procedures were performed in the IBM Statistical Package for The Social Sciences (SPSS) (v.21, IBM, New York, USA).

\section{Results}

Velocity

There was a significant and strong main effect of swim stroke $\left(\mathrm{F}_{3,69}=60.549 ; \mathrm{p}<0.001 ; \eta^{2}=0.689\right)$ and condition $\left(F_{2,46}=308.337 ; P=0.000 ; \eta^{2}=0.892\right)$ in the swim velocity and an interaction in stroke ${ }^{*}$ condition $\left(F_{6,138}=31.095\right.$; $p<0.001 ; \eta^{2}=0.556$ ) (Table 1). There were significant differences in all pairwise comparisons across conditions $(p<0.001)$ as well as in all pairwise comparisons between strokes ( $p<0.001$ ) with the exception of backstroke vs butterfly.

When analyzing the partial velocity, the sum of AS velocity and LK velocity was higher than $100 \%$ for all strokes (Table 1). For all the swim strokes, in comparison to FS, the partial contribution of the AS velocity was higher in boys and the partial contribution of the LK velocity was higher in the girls.

\section{Speed fluctuation}

A significant and strong effect of the swim stroke $\left(\mathrm{F}_{1.584,36.439}=470.784 ; \mathrm{p}<0.001 ; \eta^{2}=0.952\right)$ and condition $\left(\mathrm{F}_{2,46}=40.635 ; \mathrm{P}=0.000 ; \eta^{2}=0.560\right)$ in the $d v$ was found, as well as a stroke ${ }^{*}$ condition interaction $\left(F_{3.416,78.566}=12.729\right.$; $p<0.001 ; \eta^{2}=0.334$ ) (Table 2). With the exception of frontcrawl vs. backstroke, there were significant differences in all pairwise comparisons between swim strokes $(p<0.001)$. The

Table 1. Comparison of the swim velocity (v) for the three conditions in the four swimming strokes, its main effects and interactions.

\begin{tabular}{|c|c|c|c|c|c|c|c|}
\hline \multicolumn{8}{|c|}{ Velocity $(v, \mathrm{~m} / \mathrm{s})$} \\
\hline & & $\begin{array}{c}\text { Full stroke } \\
\text { Mean } \pm 1 \text { SD } \\
(95 \mathrm{Cl})\end{array}$ & $\begin{array}{l}\% \\
\text { FS }\end{array}$ & $\begin{array}{c}\text { Arm stroke } \\
\text { Mean } \pm 1 \text { SD } \\
(95 \mathrm{Cl})\end{array}$ & $\begin{array}{l}\% \\
\text { FS }\end{array}$ & $\begin{array}{c}\text { Leg kicking } \\
\text { Mean } \pm 1 \text { SD } \\
(95 \mathrm{Cl})\end{array}$ & $\begin{array}{l}\% \\
\text { FS }\end{array}$ \\
\hline Front-crawl & Boys & $\begin{array}{l}1.404 \pm 0.105 * \\
(1.346-1.463)\end{array}$ & 100 & $\begin{array}{l}1.234 \pm 0.1399^{t^{*}} \\
(1.158-1.311)\end{array}$ & 88 & $\begin{array}{l}0.795 \pm 0.128^{\dagger \S} \\
(0.724-0.866)\end{array}$ & 57 \\
\hline & Girls & $\begin{array}{c}1.187 \pm 0.134 \\
(1.091 \pm 1.283)\end{array}$ & 100 & $\begin{array}{l}0.934 \pm 0.220 \\
(0.777-1.092)\end{array}$ & 79 & $\begin{array}{l}0.737 \pm 0.122 \\
(0.650-0.824)\end{array}$ & 62 \\
\hline & Overall & $\begin{array}{l}1.317 \pm 0.158 \\
(1.252-1.383)\end{array}$ & 100 & $\begin{array}{l}1.114 \pm 0.228{ }^{\dagger} \\
(1.020-1.208)\end{array}$ & 84 & $\begin{array}{l}0.772 \pm 0.126^{\dagger \S} \\
(0.720-0.824)\end{array}$ & 59 \\
\hline Backstroke & Boys & $\begin{array}{l}1.178 \pm 1.117 \text { * } \\
(1.114-1.243)\end{array}$ & 100 & $\begin{array}{l}1.002 \pm 0.115^{t^{*}} \\
(0.938-1.066)\end{array}$ & 85 & $\begin{array}{l}0.782 \pm 0.099 \\
(0.727-0.870)\end{array}$ & 66 \\
\hline & Girls & $\begin{array}{c}1.042 \pm 0.143 \\
(0.940-1.144)\end{array}$ & 100 & $\begin{array}{l}0.880 \pm 0.124^{\dagger} \\
(0.791-0.968)\end{array}$ & 84 & $\begin{array}{l}0.726 \pm 0.102^{\dagger \S} \\
(0.652-0.799)\end{array}$ & 70 \\
\hline & Overall & $\begin{array}{c}1.124 \pm 0.142 \\
(1.065-1.182)\end{array}$ & 100 & $\begin{array}{l}0.953 \pm 0.131^{\dagger} \\
(0.899-1.007)\end{array}$ & 85 & $\begin{array}{l}0.759 \pm 0.102^{\dagger \S} \\
(0.717-0.802)\end{array}$ & 68 \\
\hline Breaststroke & Boys & $\begin{array}{l}1.004 \pm 0.119 * \\
(0.938-1.069)\end{array}$ & 100 & $\begin{array}{l}0.789 \pm 0.158 \text { *十 } \\
(0.702-0.877)\end{array}$ & 79 & $\begin{array}{l}0.783 \pm 0.0800^{\dagger} \\
(0.739-0.828)\end{array}$ & 78 \\
\hline & Girls & $\begin{array}{l}0.867 \pm 0.098 \\
(0.796-0.937)\end{array}$ & 100 & $\begin{array}{l}0.667 \pm 0.137^{\dagger} \\
(0.569-0.765)\end{array}$ & 77 & $\begin{array}{l}0.747 \pm 0.092^{+\S} \\
(0.681-0.813)\end{array}$ & 86 \\
\hline & Overall & $\begin{array}{c}0.949 \pm 0.129 \\
(0.896-1.002)\end{array}$ & 100 & $\begin{array}{l}0.740 \pm 0.159^{\dagger} \\
(0.675-0.806)\end{array}$ & 78 & $\begin{array}{l}0.769 \pm 0.085^{\dagger} \\
(0.734-0.804)\end{array}$ & 82 \\
\hline Butterfly & Boys & $\begin{array}{l}1.167 \pm 0.155 \text { * } \\
(1.081-1.253)\end{array}$ & 100 & $\begin{array}{l}1.050 \pm 0.198 \\
(0.940-1.159)\end{array}$ & 90 & $\begin{array}{l}0.807 \pm 0.107^{+\S^{*}} \\
(0.748-0.867)\end{array}$ & 69 \\
\hline & Girls & $\begin{array}{c}0.966 \pm 0.165 \\
(0.848-1.084)\end{array}$ & 100 & $\begin{array}{l}0.776 \pm 0.186 \\
(0.644-0.909)\end{array}$ & 80 & $\begin{array}{l}0.703 \pm 0.094^{\dagger} \\
(0.636-0.770)\end{array}$ & 73 \\
\hline & Overall & $\begin{array}{l}1.087 \pm 0.185 \\
(1.010-1.163)\end{array}$ & 100 & $\begin{array}{l}0.940 \pm 0.233^{\dagger} \\
(0.844-1.037)\end{array}$ & 86 & $\begin{array}{l}0.766 \pm 0.113^{\dagger \S} \\
(0.719-0.812)\end{array}$ & 71 \\
\hline ANOVA & & & & & & & \\
\hline & df & F-ratio & p-value & $\eta^{2}$ & & & \\
\hline Stroke & 3,69 & 60.549 & $<0.001$ & 0.689 & & & \\
\hline Condition & 2,46 & 308.337 & $<0.001$ & 0.829 & & & \\
\hline Gender & 1,23 & 12.061 & 0.002 & 0.344 & & & \\
\hline Stroke ${ }^{*}$ condition & 6,138 & 31.095 & $<0.001$ & 0.556 & & & \\
\hline Stroke ${ }^{*}$ gender & 3,69 & 4.306 & 0.008 & 0.049 & & & \\
\hline Condition ${ }^{*}$ gender & 2,46 & 14.344 & $<0.001$ & 0.042 & & & \\
\hline Stroke* condition*gender & 6,138 & 1,846 & 0.094 & 0.033 & & & \\
\hline
\end{tabular}

† - Different from full stroke for pairwise comparisons (i.e. post-hoc test); $§-$ Different from arm stroke; ${ }^{*}-$ Different from girls; $\ddagger-$ Different from overall ( $\left.p<0.05\right)$ 
Table 2. Comparison of the speed fluctuation $(d v)$ for the three conditions in the four swimming strokes, its main effects and interactions.

\begin{tabular}{|c|c|c|c|c|}
\hline \multicolumn{5}{|c|}{ Speed fluctuation ( $d v$, dimensionless) } \\
\hline & & $\begin{array}{c}\text { Full stroke } \\
\text { Mean } \pm 1 \text { SD } \\
(95 \mathrm{Cl})\end{array}$ & $\begin{array}{c}\text { Arm stroke } \\
\text { Mean } \pm 1 \mathrm{SD} \\
(95 \mathrm{Cl})\end{array}$ & $\begin{array}{c}\text { Leg kicking } \\
\text { Mean } \pm 1 \text { SD } \\
(95 \mathrm{Cl})\end{array}$ \\
\hline \multirow[t]{3}{*}{ Front-crawl } & Boys & $\begin{array}{l}7.299 \pm 1.625 * \\
(6.399-8.199)\end{array}$ & $\begin{array}{l}7.980 \pm 2.193 * \\
(6.766-9.195)\end{array}$ & $\begin{array}{l}12.223 \pm 4.405^{\dagger \S} \\
(9.783-14.663)\end{array}$ \\
\hline & Girls & $\begin{array}{r}9.648 \pm 1.796 \\
(8.363-10.933)\end{array}$ & $\begin{array}{r}11.261 \pm 3.654 \\
(8.647-13.874)\end{array}$ & $\begin{array}{r}10.149 \pm 5.895 \\
(5.932-14.366)\end{array}$ \\
\hline & Overall & $\begin{array}{l}8.239 \pm 2.032 \\
(7.400-9.078)\end{array}$ & $\begin{array}{r}9.292 \pm 3.241 \\
(7.955-10.630)\end{array}$ & $\begin{array}{l}11.393 \pm 5.043^{\dagger} \\
(9.312-13.475)\end{array}$ \\
\hline \multirow[t]{3}{*}{ Backstroke } & Boys & $\begin{array}{l}6.524 \pm 2.308 \\
(5.246-7.802)\end{array}$ & $\begin{array}{l}8.594 \pm 2.205^{\dagger} \\
(7.373-9.815)\end{array}$ & $\begin{array}{c}8.725 \pm 3.668{ }^{\dagger} \\
(6.694-10.756)\end{array}$ \\
\hline & Girls & $\begin{array}{l}7.464 \pm 3.235 \\
(5.149-9.778)\end{array}$ & $\begin{array}{c}9.771 \pm 3.614^{\dagger} \\
(7.186-12.356)\end{array}$ & $\begin{array}{r}8.479 \pm 3.313 \\
(6.109-10.849)\end{array}$ \\
\hline & Overall & $\begin{array}{l}6.900 \pm 2.693 \\
(5.788-8.012)\end{array}$ & $\begin{array}{c}9.065 \pm 2.842^{\dagger} \\
(7.892-10.238)\end{array}$ & $\begin{array}{l}8.627 \pm 3.461 \\
(7.198-10.055)\end{array}$ \\
\hline \multirow[t]{3}{*}{ Breaststroke } & Boys & $\begin{array}{r}44.266 \pm 4.770 \\
(41.625-46.908)\end{array}$ & $\begin{array}{l}36.812 \pm 7.277^{\dagger} \\
(32.782-40.84)\end{array}$ & $\begin{array}{c}49.510 \pm 6.219^{\dagger \S} \\
(46.066-52.953)\end{array}$ \\
\hline & Girls & $\begin{array}{r}46.409 \pm 1.733 \\
(45.170-47.649)\end{array}$ & $\begin{array}{c}39.066 \pm 5.565 \\
(35.085-43.057)\end{array}$ & $\begin{array}{c}51.213 \pm 5.687^{+\S} \\
(47.145-55.282)\end{array}$ \\
\hline & Overall & $\begin{array}{r}45.070 \pm 4.002 \\
(43.418-46.722)\end{array}$ & $\begin{array}{c}37.714 \pm 6.616^{\dagger} \\
(34.983-40.445)\end{array}$ & $\begin{array}{c}50.191 \pm 5.951^{+\S} \\
(47.735-52.647)\end{array}$ \\
\hline \multirow[t]{3}{*}{ Butterfly } & Boys & $\begin{array}{r}24.603 \pm 9.184 \\
(19.518-29.689)\end{array}$ & $\begin{array}{c}22.961 \pm 7.222 * \\
(18.961-26.961)\end{array}$ & $\begin{array}{c}38.580 \pm 9.793 \\
(33.157-44.004)\end{array}$ \\
\hline & Girls & $\begin{array}{l}29.362 \pm 10.188 \\
(22.074-36.650)\end{array}$ & $\begin{array}{l}32.184 \pm 12.799 \\
(23.028-41.339)\end{array}$ & $\begin{array}{c}34.260 \pm 11.956 \\
(25.707-42.813)\end{array}$ \\
\hline & Overall & $\begin{array}{r}26.507 \pm 9.684 \\
(22.509-30.504)\end{array}$ & $\begin{array}{l}26.650 \pm 10.636^{\dagger} \\
(22.260-31.040)\end{array}$ & $\begin{array}{l}36.852 \pm 10.867 \\
(32.441-41.264)\end{array}$ \\
\hline \multicolumn{5}{|l|}{ ANOVA } \\
\hline & df & F-ratio & p-value & $\eta^{2}$ \\
\hline Stroke & $1.584,36.439$ & 470.784 & $<0.001$ & 0.952 \\
\hline Condition & 2,46 & 40.635 & $<0.001$ & 0.560 \\
\hline Gender & 1,23 & 1.693 & 0.206 & 0.069 \\
\hline Stroke* condition & $3.416,78.566$ & 12.729 & $<0.001$ & 0.334 \\
\hline Stroke*gender & $1.584,36.439$ & 0.555 & 0.647 & 0.001 \\
\hline Condition*gender & 2,46 & 8.909 & 0.001 & 0.123 \\
\hline Stroke* condition* gender & $3.416,78.566$ & 2.375 & 0.069 & 0.062 \\
\hline
\end{tabular}

$\dagger$ - Different from full stroke for pairwise comparisons (i.e. post-hoc test); $\S-$ Different from arm stroke; ${ }^{*}-$ Different from girls; $\ddagger-$ Different from overall ( $\left.p<0.05\right)$

same happened in all pairwise comparisons between conditions ( $p<0.001)$ except for the FS vs AS.

\section{SampEn}

There was a significant and strong effect of the swim stroke $\left(F_{1.974,45.401}=129.449 ; P=0.000 ; \eta^{2}=0.823\right)$ and condition $\left(F_{2,46}=35.456 ; P=0.000 ; \eta^{2}=0.593\right)$ in the SampEn. There was also a stroke ${ }^{*}$ condition interaction $\left(F_{6,138}=24.998 ; p<0.001\right.$; $\eta^{2}=0.488$ ) (Table 3). Furthermore, there were significant differences between breaststroke and the remaining strokes $(p<0.001)$. Finally, significant differences were also found in all pairwise comparisons between conditions ( $p<0.001$ ), except for FS vs AS.

\section{Fractal dimension}

Regarding the FD, significant and strong effects of the swim stroke $\left(F_{1.878,41.315}=79.320 ; p<0.001 ; \eta^{2}=0.769\right)$ and condition $\left(F_{1.574,34.628}=51.427 ; p<0.001 ; \eta^{2}=0.696\right)$ were found, with a stroke*condition interaction $\left(F_{3.226,70.979}=29.774\right.$; $p<0.001 ; \eta^{2}=0.570$ ) (Table 4). There were also significant differences across all pairwise comparisons for the swim strokes $(0.001<\mathrm{P}<0.002)$. All pairwise comparisons between conditions returned significant differences $(P=0.001)$ except for FS vs AS.

\section{Discussion}

The aim of this work was to assess the effect of the limbs' actions on nonlinear properties of the four competitive swimming strokes' speed patterns. All swimming strokes and conditions showed nonlinear properties, especially a typical fractal-like behavior. Therefore, the level of predictability and complexity of these patterns changes with the number of limbs in action.

\section{Velocity}

Velocity is the most measured parameter in competitive swimming and considered the best predictor of performance (Barbosa, Marinho, Costa, \& Silva, 2011). The fastest competitive strokes in world-class swimmers are front-crawl, followed by butterfly, backstroke and breaststroke (Kennedy, Brown, Chengalur, \& Nelson, 1990). We noted the fastest strokes to be front-crawl, followed by backstroke, butterfly and breaststroke, both in the FS $\left(0.949 \pm 0.129 \mathrm{~m} \cdot \mathrm{s}^{-1}<\mathrm{v}<1.317 \pm 0.158 \mathrm{~m} \cdot \mathrm{s}^{-1}\right)$ as in the AS conditions $\left(0.740 \pm 0.159 \mathrm{~m} \cdot \mathrm{s}^{-1}<\mathrm{v}<1.114 \pm 0.228 \mathrm{~m} \cdot \mathrm{s}^{-1}\right)$. This difference between literature and our study can be 
Table 3. Comparison of sample entropy (SampEn) for the three conditions in the four swimming strokes, its main effects and interactions.

\begin{tabular}{|c|c|c|c|c|}
\hline \multicolumn{5}{|c|}{ Sample Entropy (SampEn, dimensionless) } \\
\hline & & $\begin{array}{c}\text { Full stroke } \\
\text { Mean } \pm 1 \text { SD } \\
(95 \mathrm{Cl})\end{array}$ & $\begin{array}{c}\text { Arm stroke } \\
\text { Mean } \pm 1 \text { SD } \\
(95 \mathrm{Cl})\end{array}$ & $\begin{array}{c}\text { Leg kicking } \\
\text { Mean } \pm 1 \text { SD } \\
(95 \mathrm{Cl})\end{array}$ \\
\hline \multirow[t]{3}{*}{ Front-crawl } & Boys & $\begin{array}{c}0.581 \pm 0.032 \\
(0.563-0.598)\end{array}$ & $\begin{array}{l}0.564 \pm 0.032 * \\
(0.546-0.582)\end{array}$ & $\begin{array}{l}0.575 \pm 0.056 \text { * } \\
(0.544-0.605)\end{array}$ \\
\hline & Girls & $\begin{array}{c}0.566 \pm 0.043 \\
(0.535-0.596)\end{array}$ & $\begin{array}{l}0.523 \pm 0.035 \\
(0.498-0.548)\end{array}$ & $\begin{array}{c}0.520 \pm 0.064 \\
(0.474-0.566)\end{array}$ \\
\hline & Overall & $\begin{array}{l}0.575 \pm 0.037 \\
(0.560-0.590)\end{array}$ & $\begin{array}{l}0.549 \pm 0.038 \\
(0.533-0.565)\end{array}$ & $\begin{array}{l}0.553 \pm 0.064 \\
(0.526-0.579)\end{array}$ \\
\hline \multirow[t]{3}{*}{ Backstroke } & Boys & $\begin{array}{c}0.566 \pm 0.037 \\
(0.546-0.586)\end{array}$ & $\begin{array}{c}0.544 \pm 0.030 \\
(0.528-0.561)\end{array}$ & $\begin{array}{l}0.520 \pm 0.069^{\dagger} \\
(0.482-0.558)\end{array}$ \\
\hline & Girls & $\begin{array}{l}0.547 \pm 0.044 \\
(0.516-0.579)\end{array}$ & $\begin{array}{l}0.546 \pm 0.036 \\
(0.521-0.572)\end{array}$ & $\begin{array}{l}0.504 \pm 0.082 \\
(0.446-0.563)\end{array}$ \\
\hline & Overall & $\begin{array}{l}0.558 \pm 0.040 \\
(0.542-0.575)\end{array}$ & $\begin{array}{c}0.545 \pm 0.032 \\
(0.532-0.558)\end{array}$ & $\begin{array}{l}0.514 \pm 0.073^{\dagger \S} \\
(0.484-0.544)\end{array}$ \\
\hline \multirow[t]{3}{*}{ Breaststroke } & Boys & $\begin{array}{c}0.354 \pm 0.054 \\
(0.325-0.384)\end{array}$ & $\begin{array}{c}0.409 \pm 0.083 \\
(0.363-0.455)\end{array}$ & $\begin{array}{l}0.202 \pm 0.058^{\dagger \S} \\
(0.170-0.234)\end{array}$ \\
\hline & Girls & $\begin{array}{l}0.315 \pm 0.049 \\
(0.280-0.350)\end{array}$ & $\begin{array}{l}0.449 \pm 0.054+ \\
(0.410-0.488)\end{array}$ & $\begin{array}{l}0.209 \pm 0.054^{\dagger \S} \\
(0.170-0.248)\end{array}$ \\
\hline & Overall & $\begin{array}{c}0.338 \pm 0.054 \\
(0.316-0.360)\end{array}$ & $\begin{array}{c}0.425 \pm 0.0744^{\dagger} \\
(0.394-0.455)\end{array}$ & $\begin{array}{l}0.205 \pm 0.055^{\dagger \S} \\
(0.182-0.228)\end{array}$ \\
\hline \multirow[t]{3}{*}{ Butterfly } & Boys & $\begin{array}{c}0.517 \pm 0.064 \\
(0.482-0.552)\end{array}$ & $\begin{array}{c}0.506 \pm 0.094 \\
(0.454-0.559)\end{array}$ & $\begin{array}{l}0.459 \pm 0.092 \\
(0.408-0.510)\end{array}$ \\
\hline & Girls & $\begin{array}{c}0.545 \pm 0.054 \\
(0.507-0.584)\end{array}$ & $\begin{array}{c}0.542 \pm 0.059 \\
(0.500-0.583)\end{array}$ & $\begin{array}{c}0.568 \pm 0.104 \\
(0.493-0.643)\end{array}$ \\
\hline & Overall & $\begin{array}{c}0.528 \pm 0.060 \\
(0.503-0.553)\end{array}$ & $\begin{array}{c}0.521 \pm 0.082 \\
(0.487-0.554)\end{array}$ & $\begin{array}{c}0.503 \pm 0.110 \\
(0.457-0.548)\end{array}$ \\
\hline \multicolumn{5}{|l|}{ ANOVA } \\
\hline & df & F-ratio & $p$-value & $\eta^{2}$ \\
\hline Stroke & $1.974,45.401$ & 129.449 & $<0.001$ & 0.823 \\
\hline Condition & 2,46 & 35.456 & $<0.001$ & 0.593 \\
\hline Gender & 1,23 & 0,010 & 0,920 & 0,000 \\
\hline Stroke* condition & 6,138 & 24.998 & $<0.001$ & 0.488 \\
\hline Stroke*gender & $1.974,45.401$ & 4.879 & 0.012 & 0.031 \\
\hline Condition*gender & 2,46 & 1,266 & 0,292 & 0,020 \\
\hline Stroke ${ }^{*}$ condition ${ }^{*}$ gender & 6,138 & 3.202 & 0.006 & 0.063 \\
\hline
\end{tabular}

$\dagger$ - Different from full stroke for pairwise comparisons (i.e. post-hoc test); $§-$ Different from arm stroke; ${ }^{*}-$ Different from girls; $\ddagger-$ Different from overall ( $p<0.05$ )

explained by the swimmer specialization, given that world-class swimmers tend to be specialized in only one swimming stroke. In this study, LK was the slowest condition in all strokes with the exception of breaststroke. Previous studies have reported that the propulsive force and breaststroke speed in the LK are similar or higher than for the AS (Chollet, Seifert, Leblanc, Boulesteix, \& Carter, 2004; Craig, Termin, \& Pendergast, 2006; Vorontsov \& Rumyantsev, 2000). The reason relies on the orientation of the propulsive forces generated by the legs' actions. The horizontal orientation of the leg movements in breaststroke generates greater propulsion than the other strokes, where this orientation is vertical (Vorontsov \& Rumyantsev, 2000).

Overall, the velocity for front-crawl AS found in the present study is in agreement with the $87-90 \%$ reported on segmental velocity for this stroke (Hollander et al., 1988; Ribeiro et al., 2015; Watkins \& Gordon, 1983) with slight differences between males and females also as reported in other previous interventions in the same topic (Watkins \& Gordon, 1983). Similar results obtained in the remaining swim strokes. The AS accounted for $85 \%$ of the velocity in backstroke, $78 \%$ in breaststroke and $86 \%$ in butterfly (again with slight differences between genders). Interestingly, the LK accounted for between 59 and $82 \%$ of the velocity for the different strokes, making the sum of segmental velocities greater than 100\% (front crawl: 143\%; backstroke: 153\%; breaststroke: $160 \%$ and; butterfly: 157\%). The chosen leg kicking frequency during swimming seems to be a natural process, as each leg kick matches a specific arms' action (Yanai, 2003). Without the arms' actions, swimmers may choose a higher leg kicking rate, as legs are no longer dependent on the arm/leg coordination. The absence of the arm pull also makes the legs the main propellant, thus, swimmers need to kick faster to maintain the body's horizontal position and move forward (Yanai \& Wilson, 2008). In line with this, our results suggest that there is a typical task constraint in the FS condition in all four strokes, that lead to a loss of efficiency between the segmental strokes and the style as a whole, where kick-to-stroke rate may be the main influencing factor.

\section{Speed fluctuation}

Speed fluctuation is a key-variable to be assessed in competitive swimming (Kolmogorov \& Duplishcheva, 1992). It allows: (i) the identification of critical issues or mistakes over the stroke cycle; (ii) collection of relevant data for practitioners; (iii) determination of swimming economy (Barbosa, Bragada, et al. 2010). The $d v$ is influenced by both the thrust and drag force. The swim strokes that produce higher variations in these external forces over the cycle, also present the highest $d v$, therefore being related with energy cost (Barbosa et al., 2005; Vilas-Boas, Vilas-Boas, Barbosa, \& Fernandes, 2010). So, a swimmer with a lower $d v$ value has a higher swimming efficiency, as high variations on $d v$ require extra energy to overcome inertial forces. 
Table 4. Comparison of the fractal dimension (FD) for the three conditions in the four swimming strokes, its main effects and interactions.

\begin{tabular}{|c|c|c|c|c|}
\hline \multicolumn{5}{|c|}{ Fractal dimension (FD, dimensionless) } \\
\hline & & $\begin{array}{c}\text { Full stroke } \\
\text { Mean } \pm 1 \text { SD } \\
(95 \mathrm{Cl})\end{array}$ & $\begin{array}{c}\text { Arm stroke } \\
\text { Mean } \pm 1 \text { SD } \\
(95 \mathrm{Cl})\end{array}$ & $\begin{array}{c}\text { Leg kicking } \\
\text { Mean } \pm 1 \text { SD } \\
(95 \mathrm{Cl})\end{array}$ \\
\hline \multirow[t]{3}{*}{ Front-crawl } & Boys & $\begin{array}{l}1.9191 \pm 0.022 \\
(1.907-1.931)\end{array}$ & $\begin{array}{l}1.9176 \pm 0.021 \\
(1.906-1.929)\end{array}$ & $\begin{array}{l}1.8747 \pm 0.048^{\dagger \S} \\
(1.848-1.901)\end{array}$ \\
\hline & Girls & $\begin{array}{l}1.9096 \pm 0.016 \\
(1.898-1.921)\end{array}$ & $\begin{array}{l}1.9253 \pm 0.023 \\
(1.909-1.942)\end{array}$ & $\begin{array}{l}1.8298 \pm 0.071^{+\S} \\
(1.779-1.880)\end{array}$ \\
\hline & Overall & $\begin{array}{l}1.9153 \pm 0.020 \\
(1.907-1.924)\end{array}$ & $\begin{array}{l}1.9205 \pm 0.021 \\
(1.912-1.929)\end{array}$ & $\begin{array}{l}1.8567 \pm 0.061^{t \S} \\
(1.832-1.882)\end{array}$ \\
\hline \multirow[t]{3}{*}{ Backstroke } & Boys & $\begin{array}{l}1.8904 \pm 0.042 \\
(1.867-1.914)\end{array}$ & $\begin{array}{l}1.9126 \pm 0.031 \\
(1.896-1.930)\end{array}$ & $\begin{array}{l}1.7771 \pm 0.077^{+\S} \\
(1.734-1.820)\end{array}$ \\
\hline & Girls & $\begin{array}{l}1.8732 \pm 0.032 \\
(1.850-1.896)\end{array}$ & $\begin{array}{l}1.9069 \pm 0.041 \\
(1.877-1.936)\end{array}$ & $\begin{array}{l}1.7644 \pm 0.085^{\dagger \S} \\
(1.703-1.826)\end{array}$ \\
\hline & Overall & $\begin{array}{l}1.8835 \pm 0.039 \\
(1.868-1.899)\end{array}$ & $\begin{array}{l}1.9103 \pm 0.035^{\dagger} \\
(1.896-1.925)\end{array}$ & $\begin{array}{l}1.7720 \pm 0.079^{t \S} \\
(1.739-1.805)\end{array}$ \\
\hline \multirow[t]{3}{*}{ Breaststroke } & Boys & $\begin{array}{l}1.9553 \pm 0.010 \\
(1.950-1.961)\end{array}$ & $\begin{array}{l}1.9494 \pm 0.014 \\
(1.942-1.957)\end{array}$ & $\begin{array}{l}1.9496 \pm 0.012 \\
(1.943-1.956)\end{array}$ \\
\hline & Girls & $\begin{array}{l}1.9549 \pm 0.008 \\
(1.949-1.961)\end{array}$ & $\begin{array}{l}1.9517 \pm 0.011 \\
(1.944-1.959)\end{array}$ & $\begin{array}{l}1.9511 \pm 0.009 \\
(1.945-1.958)\end{array}$ \\
\hline & Overall & $\begin{array}{l}1.9551 \pm 0.009 \\
(1.951-1.959)\end{array}$ & $\begin{array}{l}1.9503 \pm 0.012 \\
(1.945-1.955)\end{array}$ & $\begin{array}{l}1.9502 \pm 0.011 \\
(1.946-1.955)\end{array}$ \\
\hline \multirow[t]{3}{*}{ Butterfly } & Boys & $\begin{array}{l}1.9510 \pm 0.004 \\
(1.949-1.953)\end{array}$ & $\begin{array}{l}1.9350 \pm 0.014^{\dagger} \\
(1.927-1.943)\end{array}$ & $\begin{array}{l}1.9522 \pm 0.006^{\S} \\
(1.949-1.955)\end{array}$ \\
\hline & Girls & $\begin{array}{l}1.9491 \pm 0.011 \\
(1.941-1.957)\end{array}$ & $\begin{array}{l}1.9330 \pm 0.013^{\dagger} \\
(1.924-1.942)\end{array}$ & $\begin{array}{l}1.9477 \pm 0.011 \S \\
(1.940-1.956)\end{array}$ \\
\hline & Overall & $\begin{array}{l}1.9501 \pm 0.008 \\
(1.947-1.953)\end{array}$ & $\begin{array}{l}1.9342 \pm 0.013^{\dagger} \\
(1.929-1.940)\end{array}$ & $\begin{array}{l}1.9503 \pm 0.009 \S \\
(1.947-1.954)\end{array}$ \\
\hline \multicolumn{5}{|l|}{ ANOVA } \\
\hline & df & F-ratio & $\mathrm{p}$-value & $\eta^{2}$ \\
\hline Stroke & $1.878,41.315$ & 79.320 & 0.000 & 0.769 \\
\hline Condition & $1.574,34.628$ & 51.427 & 0.000 & 0.696 \\
\hline Gender & 1,22 & 2.545 & 0.125 & 0.104 \\
\hline Stroke ${ }^{*}$ condition & $3.226,70.979$ & 29.774 & 0.000 & 0.570 \\
\hline Stroke* gender & $1.878,41.315$ & 1.716 & 0.194 & 0.017 \\
\hline Condition* gender & $1.574,34.628$ & 0.616 & 0.508 & 0.006 \\
\hline Stroke* condition*gender & $3.226,70.979$ & 0.437 & 0.741 & 0.010 \\
\hline
\end{tabular}

† - Different from full stroke for pairwise comparisons (i.e. post-hoc test); $§-$ Different from arm stroke; ${ }^{*}-$ Different from girls; $\ddagger-$ Different from overall $(p<0.05)$

Unlike the nonlinear variables, detailed below, $d v$ is well known to be dependent on limbs' movements. $d v$ also brings insight on the inter-limb coordination (Leblanc, Seifert, Tourny-Chollet, \& Chollet, 2007; Schnitzler, Seifert, Ernwein, \& Chollet, 2008) as specific limb actions over the stroke cycle are able to decrease/ increase the $d v$ (Barbosa, Fernandes, Morouco, \& Vilas-Boas, 2008; Sanders, Cappaert, \& Pease, 1998; Silva et al., 2008).

For all conditions, the strokes with higher $d v$ were breaststroke, followed by butterfly, front-crawl and backstroke. This result is in agreement with literature (Barbosa et al., 2013) where breaststroke and butterfly have a clear higher $d v$ than front-crawl and backstroke. The conditions with the highest and the lowest $d v$ were LK and FS, respectively. In literature, $d v$ is reported as being inversely related to velocity (Barbosa, Bragada, et al. 2010; Barbosa et al., 2013). This correlation justifies our results, given that, with the exception of breaststroke, velocity increased from LK to FS.

\section{SampEn}

SampEn provides insight of the randomness of the inter-cyclic variations over the time-series. The lower its value, the higher the predictability of the time-series. The swim strokes with higher SampEn were the same among the three conditions, with front-crawl displaying the highest value, followed by backstroke, butterfly and breaststroke. These results ranged between $0.202 \leq$ SampEn $\leq 0.581$ (boys' breaststroke LK and boys' front-crawl FS, respectively). The values obtained in the FS condition, in the four swim strokes, were slightly lower than those found in the few research that computed the entropy of human swimming (Barbosa, Goh, Morais, \& Costa, 2016; Barbosa, Goh, Morais, Costa, \& Pendergast, 2016). However, different algorithms return slightly different outcomes which could explain the difference in the order of the strokes' entropy.

There is again a clear difference between the strokes with simultaneous arms and legs actions, and the remaining strokes. Although less complex, front-crawl and backstroke's swimming patterns showed to be less predictable. Contributing to this outcome could be the task constraint of synchronizing four alternated limbs, each one in a different phase of the motor path, adding a full body rotation in backstroke's case. Whereas in strokes with simultaneous limbs' actions, two of the 4 limbs are always in the same phase. We found that the FS condition exhibited a higher SampEn than the AS and LK conditions in all strokes. This is in accordance with what was stated above, as in FS there are more limbs to coordinate.

\section{Fractal dimension}

FD provides information about the intra-cyclic complexity and irregularity of a given time-series variations. The higher the FD, 
the more complex and irregular the behavior is. The FD varies according to the swim stroke and the level of expertise (Barbosa, Goh, Morais, \& Costa, 2016; Barbosa, Goh, Morais, Costa, \& Pendergast, 2016). This study is a follow-up providing evidence that the variations in nonlinear parameters are also dependent on the number of limbs in action, which confirmed the tested hypothesis.

The significant main effect of swimming stroke on FD verified in the present study is in accordance with the scarce literature (Barbosa, Goh, Morais, \& Costa, 2016; Barbosa, Goh, Morais, Costa, \& Pendergast, 2016). Adding on to their findings, in our work, the swim strokes with higher FD in their swimming patterns, and therefore with a more complex behavior, are the same, independently of sex, expertise and swimming condition: breaststroke followed by butterfly, front crawl and backstroke (the exception is the LK condition, having butterfly the highest FD). One may argue that both breaststroke and butterfly, which feature simultaneous action by both upper- and lowerlimbs, influence the complexity of the strokes' behavior, and therefore lead to higher FD. The conditions with higher FD were different across the swim strokes. The strokes with the least complex swimming patterns were front-crawl and backstroke, given that they showed the lowest FD. In fact, LK in front crawl and backstroke exhibited the lowest FD value of all conditions of all strokes $(1.8567 \pm 0.061$ and $1.7720 \pm 0.079$, respectively). This is probably due to the less complexity of the leg kicking in these strokes, which is made of only two movements that are mostly in the vertical plane (upbeat and downbeat).

According to Seifert, Seifert, Chollet, and Bardy (2004), finding the best swimming pace associated with the swimmer's arm coordination, or conversely, adapting the arm coordination when it is not compatible with the swimming pace, is part of the exploration and learning process. In agreement with the nonlinear pedagogy, the manipulation of this constraint could help a preferential coordination pattern to emerge, that can then be stabilized for specialization (Seifert, Chollet, \& Rouard, 2007). In our study, all swimming strokes and conditions exhibited long-time correlations, i.e. fractal-like behavior. The swimming patterns of the swim strokes featuring simultaneous action by both upper- and lower-limbs (i.e. breaststroke and butterfly) are less random than the other two, however, more complex. The LK condition is less complex than AS and FS conditions. Interestingly, some teaching programmes even advise pupils to learn first front-crawl and backstroke (Costa, Barbosa, Morais, Miranda, \& Marinho, 2017), and the findings herein seem to backup such assumption.

\section{Practical applications}

The results of our study can help the swimming teacher to be aware of the complexity level of each limb action in each swimming stroke pattern. This awareness enables the creation of task constraints resorting to arms' and/or legs' actions to complicate or simplify a specific task in order to facilitate the learning of a specific skill.

\section{Limitations and future perspectives}

Some limitations can be raised for this study: (i) two different periods of the day were used to perform the data collection, and it may have affected the swimmer's performances; (ii) it is unclear if the same findings would be obtained in elite and master swimmers, albeit in these groups of swimmers are prone to be highly-specialized in only one or two strokes; (iii) follow-up studies should try to understand the role of drag and thrust on the nonlinear swimming behavior; (iv) it would also be interesting to understand the changes in the nonlinear behavior swimming at different paces because in this research participants performed all-out bouts.

\section{Conclusions}

It can be concluded that the four competitive strokes exhibit nonlinear properties, performing the full stroke, and only the upper- or lower-limbs actions. The swimming patterns are less complex and more predictable performing the kicking when compared to the arm-pull stroke and full stroke. Comparing the four competitive strokes, breaststroke and butterfly have more complex but more predictable swimming patterns compared to backstroke and front-crawl.

\section{Acknowledgements}

The authors would like to express their sincere gratitude to: i) all the coaches for their support and the swimmers who participated in this study, and; ii) Dr. Márcio Carocho for the assistance in reviewing the English language.

\section{Disclosure statement}

No potential conflict of interest was reported by the authors.

\section{Funding}

This project was supported by the National Funds through FCT Portuguese Foundation for Science and Technology (UID/DTP/04045/ 2013) - and the European Fund for regional development (FEDER) allocated by European Union through the COMPETE 2020 Programme (POCI01-0145-FEDER-006969); European Regional Development Fund [POCI-010145-FEDER-006969]; Fundação para a Ciência e a Tecnologia [UID/DTP/ 04045/2013].

\section{ORCID}

Raul F. Bartolomeu (D) http://orcid.org/0000-0001-8557-5257

Mário J. Costa (1) http://orcid.org/0000-0001-5502-1202

Tiago M. Barbosa (D) http://orcid.org/0000-0001-7071-2116

\section{References}

Araújo, D., Davids, K., Bennett, S. J., Button, C., \& Chapman, G. (2004). Emergence of sport skills under constraints. In A. M. Williams \& N. Hodges (Eds.), Skill acquisition in sport: Research, theory and practice (pp. 409). London: Routledge.

Barbosa, T. M., Bragada, J. A., Reis, V. M., Marinho, D. A., Carvalho, C., \& Silva, A. J. (2010). Energetics and biomechanics as determining factors of swimming performance: Updating the state of the art. Journal of Science and Medicine in Sport / Sports Medicine Australia, 13(2), 262-269. doi:10.1016/j.jsams.2009.01.003 
Barbosa, T. M., Costa, M. J., \& Marinho, D. A. (2013). Proposal of a deterministic model to explain swimming performance. International Journal of Swimming Kinetics, 2(1), 1-54.

Barbosa, T. M., Costa, M. J., Morais, J. E., Morouço, P., Moreira, M., Garrido, N. D., ... Silva, A. J. (2013). Characterization of speed fluctuation and drag force in young swimmers: A gender comparison. Human Movement Science, 32(6), 1214-1225. doi:10.1016/j.humov.2012.07.009

Barbosa, T. M., Fernandes, R. J., Morouco, P., \& Vilas-Boas, J. P. (2008). Predicting the intra-cyclic variation of the velocity of the centre of mass from segmental velocities in butterfly stroke: A pilot study. Journal of Sports Science \& Medicine, 7(2), 201-209.

Barbosa, T. M., Goh, W. X., Morais, J. E., \& Costa, M. J. (2016). Variation of linear and nonlinear parameters in the swim strokes according to the level of expertise. Motor Control, 21(3), 1-27.

Barbosa, T. M., Goh, W. X., Morais, J. E., Costa, M. J., \& Pendergast, D. (2016), Comparison of classical kinematics, entropy, and fractal properties as measures of complexity of the motor system in swimming. Frontiers in Psychology, 7, 1566. doi:10.3389/fpsyg.2016.01566

Barbosa, T. M., Keskinen, K. L., Fernandes, R., Colaco, P., Lima, A. B., \& Vilas-Boas, J. P. (2005). Energy cost and intracyclic variation of the velocity of the centre of mass in butterfly stroke. European Journal of Applied Physiology, 93(5-6), 519-523. doi:10.1007/s00421-0041251-x

Barbosa, T. M., Lima, F., Portela, A., Novais, D., Machado, L., Colaço, P., ... Vilas-Boas, J. P. (2006). Relationships between energy cost, swimming velocity and speed fluctuation in competitive swimming strokes. In Revista Portuguesa de Ciências do Desporto (pp. 192-194). Porto: Faculdade de Desporto da Universidade do Porto.

Barbosa, T. M., Marinho, D. A., Costa, M. J., \& Silva, A. J. (2011). Biomechanics of competitive swimming strokes. In V. Klika (Ed.), Biomechanics in Applications (pp. 367-388). Rijeka: InTech.

Barbosa, T. M., Morouco, P. G., Jesus, S., Feitosa, W. G., Costa, M. J., Marinho, D. A., ... Garrido, N. D. (2013). The interaction between intra-cyclic variation of the velocity and mean swimming velocity in young competitive swimmers. International Journal of Sports Medicine, 34(2), 123-130.

Chen, W., Zhuang, J., Yu, W., \& Wang, Z. (2009). Measuring complexity using FuzzyEn, ApEn, and SampEn. Medical Engineering \& Physics, 31(1), 61-68. doi:10.1016/j.medengphy.2008.04.005

Chollet, D., Seifert, L., Leblanc, H., Boulesteix, L., \& Carter, M. (2004). Evaluation of arm-leg coordination in flat breaststroke. International Journal of Sports Medicine, 25(7), 486-495. doi:10.1055/s-2004820943

Chow, J. Y., Davids, K., Button, C., Shuttleworth, R., Renshaw, I., \& Araujo, D. (2006). Nonlinear pedagogy: A constraints-led framework for understanding emergence of game play and movement skills. Nonlinear Dynamics, Psychology, and Life Sciences, 10(1), 71-103.

Costa, M. J., Barbosa, T. M., Morais, J. E., Miranda, S., \& Marinho, D. A. (2017). Can concurrent teaching promote equal biomechanical adaptations at front crawl and backstroke swimming? Acta of Bioengineering and Biomechanics, 19, 1.

Craig, A. B., Jr., Termin, B., \& Pendergast, D. R. (2006). Simultaneous recordings of velocity and video during swimming. Portuguese Journal of Sport Sciences, 6(2), 32-35.

Davids, K., Button, C., \& Bennett, S. (2008). Dynamics of skill acquisition: A constraints-led approach. Champaign, IL: Human Kinetics.

Davids, K., Araujo, D., Hristovski, R., Serre, N. B., Button, C., \& Passos, P. (2014). Complex systems in sport. London: Routledge, Taylor \& Francis Group.

Delignieres, D., Ramdani, S., Lemoine, L., Torre, K., Fortes, M., \& Ninot, G. (2006). Fractal analyses for 'short'time series: A re-assessment of classical methods. Journal of Mathematical Psychology, 50(6), 525-544. doi:10.1016/j.jmp.2006.07.004

Esteller, R., Vachtsevanos, G., Echauz, J., \& Litt, B. (2001). A comparison of waveform fractal dimension algorithms. IEEE Transactions on Circuits and Systems I: Fundamental Theory and Applications, 48(2), 177-183. doi:10.1109/81.904882

Ferguson, C. J. (2009). An effect size primer: A guide for clinicians and researchers. Professional Psychology: Research and Practice, 40(5), 532 538. doi:10.1037/a0015808
Hausdorff, J. M., Peng, C. K., Ladin, Z., Wei, J. Y., \& Goldberger, A. L. (1995). Is walking a random walk? Evidence for long-range correlations in stride interval of human gait. Journal of Applied Physiology, 78(1), 349-358. doi:10.1152/jappl.1995.78.1.349

Higuchi, T. (1988). Approach to an irregular time series on the basis of the fractal theory. Physica D: Nonlinear Phenomena, 31(2), 277-283. doi:10.1016/0167-2789(88)90081-4

Hollander, A. P., de Groot, G., van Ingen Schenau, G. J., Kahman, R., \& Toussaint, H. M. (1988). Contribution of the legs to propulsion in front crawl swimming. Swimming science V. B. E. Ungerechts, K. Wilke and R. $K$ (pp. 39-43). Chamaign, IL: Human Kinetics.

Kennedy, P. M., Brown, P., Chengalur, S. N., \& Nelson, R. C. (1990). Analysis of male and female Olympic swimmers in the 100-meter events. International Journal of Sport Biomechanics, 6(2), 187-197. doi:10.1123/ijsb.6.2.187

Kolmogorov, S. V., \& Duplishcheva, O. A. (1992). Active drag, useful mechanical power output and hydrodynamic force coefficient in different swimming strokes at maximal velocity. Journal of Biomechanics, 25 (3), 311-318. doi:10.1016/0021-9290(92)90028-Y

Leblanc, H., Seifert, L., Tourny-Chollet, C., \& Chollet, D. (2007). Intra-cyclic distance per stroke phase, velocity fluctuations and acceleration time ratio of a breaststroker's hip: A comparison between elite and nonelite swimmers at different race paces. International Journal of Sports Medicine, 28(2), 140-147. doi:10.1055/s-2006-924205

Madeiro, J. P. V., Seisdedos, C. R. V., Cortez, P. C., \& Marques, J. A. L. (2013). Análise de Desempenho da Entropia Aproximada (ApEn) na Análise da Variabilidade da Frequência Cardíaca (VFC). In J. Folgueras Méndez, T. Y. Aznielle Rodríguez, C. F. Calderón Marín, S. B. Llanusa Ruiz, J. Castro Medina, H. Vega Vázquez, ... R. Rodríguez Rojas (Eds.), V Latin American Congress on Biomedical Engineering CLAIB 2011 May 16-21, 2011, Habana, Cuba: Sustainable Technologies for the Health of All (pp. 1182-1185). Berlin, Heidelberg: Springer Berlin Heidelberg.

Miyashita, M. (1971, September 14-16, 1970). An analysis of fluctuations of swimming speed. In Proceedings of the First International Symposium on Biomechanics in Swimming waterpolo and Diving, Brussels (pp. 53-57). Brussels: Université libre de Bruxelles, Laboratoire de l'Effort.

Newell, K. M. (1986). Constraints on the development of coordination. Motor Development in Children: Aspects of Coordination and Control, 34, 341-360.

Ribeiro, J., Figueiredo, P., Sousa, A., Monteiro, J., Pelarigo, J., Vilas-Boas, J. P., ... Fernandes, R. F. (2015). VO2 kinetics and metabolic contributions during full and upper body extreme swimming intensity. European Journal of Applied Physiology, 115(5), 1117-1124. doi:10.1007/s00421-014-3093-5

Richman, J. S., \& Moorman, J. R. (2000). Physiological time-series analysis using approximate entropy and sample entropy. American Journal of Physiology - Heart and Circulatory Physiology, 278(6), H2039-H2049. doi:10.1152/ajpheart.2000.278.6.H2039

Robeva, R., Kirkwood, J. R., Davies, R. L., Farhy, L., Kovatchev, B. P., Straume, M., \& Johnson, M. L. (2007). An invitation to biomathematics. Orlando, FL: Academic press.

Sanders, R. H., Cappaert, J. M., \& Pease, D. L. (1998). Wave characteristics of Olympic breaststroke swimmers. Journal of Applied Biomechanics, 14(1), 40-51. doi:10.1123/jab.14.1.40

Schiffman, J. M., Chelidze, D., Adams, A., Segala, D. B., \& Hasselquist, L. (2009). Nonlinear analysis of gait kinematics to track changes in oxygen consumption in prolonged load carriage walking: A pilot study. Journal of Biomechanics, 42(13), 2196-2199. doi:10.1016/j.jbiomech.2009.06.011

Schnitzler, C., Seifert, L., Ernwein, V., \& Chollet, D. (2008). Arm coordination adaptations assessment in swimming. International Journal of Sports Medicine, 29(6), 480-486. doi:10.1055/s-2007-989235

Seifert, L., Chollet, D., \& Bardy, B. G. (2004). Effect of swimming velocity on arm coordination in the front crawl: A dynamic analysis. Journal of Sports Sciences, 22(7), 651-660. doi:10.1080/02640410310001655787

Seifert, L., Chollet, D., \& Rouard, A. (2007). Swimming constraints and arm coordination. Human Movement Science, 26(1), 68-86. doi:10.1016/j. humov.2006.09.003

Silva, A. J., Marinho, D. A., Reis, V. M., Alves, F. B., Vilas-Boas, J. P., Machado, L., \& Rouboa, A. I. (2008). Study of the propulsive potential of the hand and forearm in swimming. Medicine \& Science in Sports \& Exercise, 40(5), S212. doi:10.1249/01.mss.0000322372.12007.0f 
Vilas-Boas, J. P., Barbosa, T. M., \& Fernandes, R. J. (2010). Speed fluctuation, swimming economy, performance and training in swimming. In L. Seifert, D. Chollet, \& I. Mujika (Eds.), World book of swimming: From science to performance (pp. 119-134). New York: Nova Science Publishers.

Vorontsov, A., \& Rumyantsev, V. (2000). Propulsive forces in swimming. In V. Zatsiorsky (Ed.) Biomechanics in sport-Performance, enhancement and injury prevention (pp. 205-231). Cambridge: Blackwell Science Ltd.

Wang, Q., Sourina, O., \& Nguyen, M. K. (2011). Fractal dimension based neurofeedback in serious games. The Visual Computer, 27(4), 299-309. doi:10.1007/s00371-011-0551-5

Watkins, J., \& Gordon, A. T. (1983, June 21-25, 1982). The effects of leg action on performance in the sprint front crawl stroke. In A. P. Hollander, P. A. Huijing, \& G. de Groot (Eds.), Proceedings of the Fourth International Symposium of Biomechanics in Swimming and the Fifth International Congress on Swimming Medicine, Amsterdam (pp. 310314). Champaign, IL, Human Kinetics.
Wuehr, M., Schniepp, R., Pradhan, C., Ilmberger, J., Strupp, M., Brandt, T., \& Jahn, K. (2013). Differential effects of absent visual feedback control on gait variability during different locomotion speeds. Experimental Brain Research. Experimentelle Hirnforschung. Experimentation Cerebrale, 224(2), 287-294. doi:10.1007/s00221-0123310-6

Yanai, T. (2003). Stroke frequency in front crawl: Its mechanical link to the fluid forces required in non-propulsive directions. Journal of Biomechanics, 36(1), 53-62. doi:10.1016/S0021-9290(02)00299-3

Yanai, T., \& Wilson, B. D. (2008). How does buoyancy influence front-crawl performance? Exploring the assumptions. Sports Technology, 1(2-3), 89-99. doi:10.1080/19346182.2008.9648458

Yentes, J. M., Hunt, N., Schmid, K. K., Kaipust, J. P., McGrath, D., \& Stergiou, N. (2013). The appropriate use of approximate entropy and sample entropy with short data sets. Annals of Biomedical Engineering, 41(2), 349-365. doi:10.1007/s10439-012-0668-3 